\title{
Sexual Transmission
}

National Cancer Institute

\section{Source}

National Cancer Institute. Sexual Transmission. NCI Thesaurus. Code C19085.

Passage or transfer, as of a disease, from a donor individual to a recipient during or as a result of sexual activity. $(\mathrm{NCl})$ 